\title{
Ageing-Related Features of Hair and Scalp in Chinese Women by Clinical Evaluation Study
}

\author{
Sehyun Kim¹, Su Na Kim¹, Susun An¹, Jae Ho Yeon², Xuemin Wang³, Li Li', Wei Lai', Hong Liang6, \\ Xinghua Gao7, Wei Liu ${ }^{8}$, Won Seok Park ${ }^{1 *}$, Yongjoo $\mathrm{Na}^{{ }^{*}}$ \\ ${ }^{1}$ AMOREPACIFIC Corp, R\&D Center, Gyeonggi-do, South Korea \\ ${ }^{2}$ AMOREPACIFIC Corp, Shanghai R\&I Center, Shanghai, China \\ ${ }^{3}$ Skin \& Cosmetic Research Department, Shanghai Skin Disease Hospital, Shanghai, China \\ ${ }^{4}$ Department of Dermato-Venereology, West China Hospital, Sichuan University, Chengdu, China \\ ${ }^{5}$ Department of Dermatology, The Third Affiliated Hospital of Sun Yat-Sen University, Guangzhou, China \\ ${ }^{6}$ Department of Dermatology, Renmin Hospital of Wuhan University, Wuhan, China \\ ${ }^{7}$ National Key Department of Dermatology and Venereology, The First Hospital of China Medical University, Shenyang, China \\ ${ }^{8}$ Department of Dermatology, The General Hospital of Air Force, Beijing, China \\ Email: *wspark@amorepacific.com, ^nay@amorepacific.com
}

How to cite this paper: Kim, S., Kim, S.N., An, S., Yeon, J.H., Wang, X.M., Li, L., Lai, W., Liang, H., Gao, X.H., Liu, W., Park, W.S. and Na, Y. (2017) Ageing-Related Features of Hair and Scalp in Chinese Women by Clinical Evaluation Study. Journal of Cosmetics, Dermatological Sciences and Applications, 7, 245-257. https://doi.org/10.4236/jcdsa.2017.73023

Received: August 10, 2017

Accepted: September 18, 2017

Published: September 25, 2017

Copyright $(2017$ by authors and Scientific Research Publishing Inc. This work is licensed under the Creative Commons Attribution International License (CC BY 4.0).

http://creativecommons.org/licenses/by/4.0/

(c) (i) Open Access

\begin{abstract}
There are previous studies of ageing hair and scalp in Caucasians and some Asians, such as Koreans and Japanese. However, the characteristics of scalp and hair have not yet been studied in Chinese, the largest population in the world, especially in terms of ageing. The purpose of this study is to investigate ageing features in Chinese women's hair and scalp. Methods: In total, 1343 women in China aged 20 to 65 participated in this research. Hair density and diameter were measured and analysed with Folliscope $e^{\oplus}$. Hair color and scalp conditions such as dandruff and erythema were evaluated through microscopic images. Measuring equipment was also used to detect scalp water content, barrier function and sebum secretion. Results: Hair density decreased gradually with ageing, while hair diameter peaked at 40s. The color of hair became bright with ageing because of gray hair and color fading. The degree of scalp sebum and dandruff was higher at younger ages. Interestingly, scalp erythema became more severe with ageing. Conclusion: This study shows the physical and physiological changes of Chinese women's hair and scalp. Most aging features (hair diameter, scalpsebum contents, dandruff and erythema) were noticeable in their 40s, but hair density began to decline in their 30s. This first study of aging hair and scalp in Chinese women would be helpful for understanding the ageing phenomenon and development of hair and scalp care products.
\end{abstract}

\section{Keywords}

Ageing, Hair, Scalp 


\section{Introduction}

Ageing appears in various ways throughout the body. Like skin, hair undergoes physical and physiological changes over time. Hair loss [1] [2] and gray hair [3] [4] [5] are typical senescence features, but there are many other factors, such as hair color fading and scalp water content, sebum secretion, dandruff and redness.

The characteristics of ageing hair in Asian women have been studied previously. In Korean women, for example, the average hair diameter was highest in their 20s, maintained steadily until 50, and then decreased significantly [6]. Japanese women showed a tendency to increase until their 40 s, and then declined with age [7]. It is interesting that there are differences in the symptoms of hair ageing among Asians. It also implies that there are perhaps regional and ethnic differences in the changing aspects.

Since China accounts for about $30 \%$ of the Asian population, it is important and necessary to study the ageing features of Chinese hair and scalp to understand those of Asians. Because of its enormous territory, there may be geological differences. For instance, androgenic alopecia was revealed differently among subjects from 6 cities in China [8]. Many aging factors can also be affected where people live.

In this study, we first investigated an ageing scalp which has been hardly known as well as hair of Chinese women by measuring their hair and scalp conditions with various instruments, evaluating by investigators and surveying subjects (Figure 1). We found that there are similarities and differences in hair and scalp parameters through ageing between Asians like Chinese and Korean.

\section{Subjects and Methods}

\subsection{Subjects}

A total of 1343 Han Chinese women aged 20 to 65 living in 6 cities of Guangzhou, Shanghai, Beijing, Wuhan, Chengdu and Shenyang in China were enrolled for this study from 2011 to 2012. Those 6 cities were selected because they are China's representative major cities and are distributed over various areas, from north to south and from coast to inland. Because all the subjects in 6 cities were

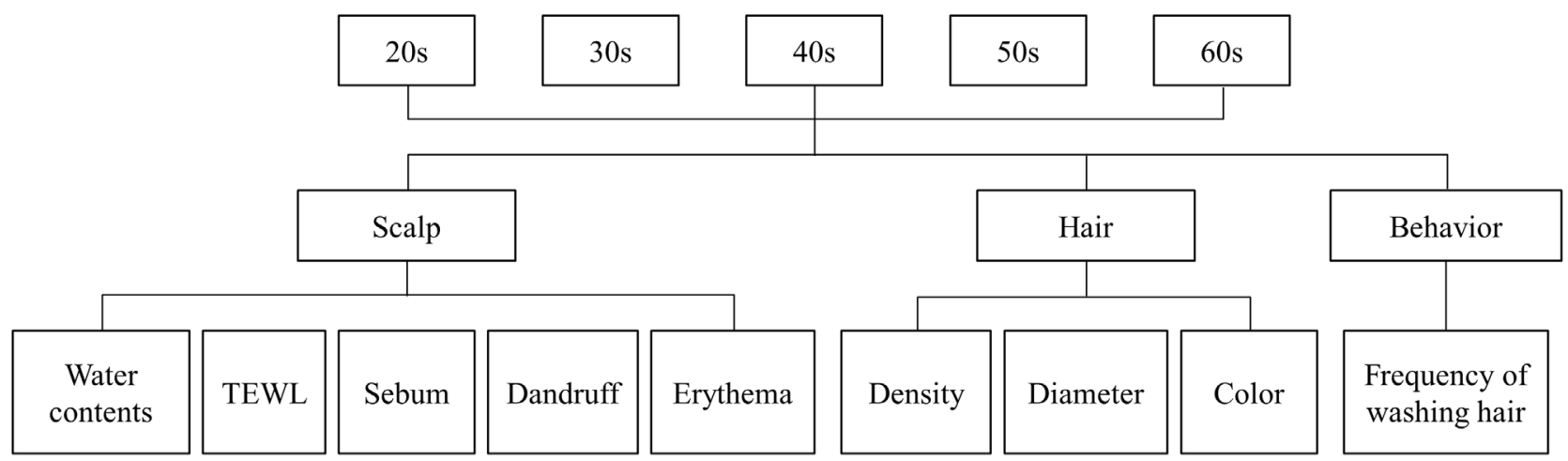

Figure 1. The procedure diagram of this study. Measurements, evaluations and surveys were conducted with 5 age groups. 
Han Chinese, there was no ethnic difference, but differences arise from climate and environment would be exist. The volunteers met the requirements of not having infectious skin disease, severe hair loss and surgical treatment on their scalp, chemical treatment on their hair such as dyeing and permanent waves for the 3 months preceding the measurements. The numbers of subjects in each group were shown in Table 1. They washed their hair using the shampoo distributed on the previous day. We have provided detailed information on this study to all subjects and obtained their consent to participate. This research was approved by the Institutional Review Board.

\subsection{Hair Density and Diameter}

Hair density and diameter were measured with Folliscope ${ }^{\circledast}$ (Lead M corp., Korea) [9]. Three photographs of the mid-line on the vertex area with 2-cm intervals were taken by a $60 \times$ magnification lens. Results were analyzed using Folliscope $\mathrm{PT}^{\oplus}$ software (Lead M corp., Korea). The total number of hairs in each digital image was counted by mouse point click, then the hair density $\left(\mathrm{N} / \mathrm{cm}^{2}\right)$ was converted automatically. The average hair density of each subject was calculated from three photographs. The measurement of hair diameter was conducted by mouse point dragging of each hair shaft then averaged from 10 hairs.

\subsection{Hair Color}

Hair color was examined in two ways: the lightness value was measured using a Spectrophotometer ${ }^{\circledR}$ CM-2600D (Minolta, Osaka, Japan) and evaluated visually by the investigators. The criteria for evaluating gray hair were determined by the gray hair portion of the total hair: Grade 1: no gray hair, Grade 2: less than 20\%, Grade 3: $20 \%$ - 40\%, Grade 4: $40 \%$ - 60\%, Grade 5: more than $60 \%$ of total hair. The grade of fading hair was determined by the uniformity of the entire hair color: Grade 1: even hair tone overall, Grade 2: generally even hair tone but with slightly uneven parts, Grade 3: many parts are slightly uneven, Grade 4: there is a part of distinctly different color, Grade 5: many parts are

Table 1. Subject information.

\begin{tabular}{|c|c|c|c|c|c|c|c|c|}
\hline & & Beijing & Shanghai & Chengdu & Guangzhou & Shenyang & Wuhan & Total \\
\hline \multirow{5}{*}{$\mathrm{N}$} & $20 s$ & 90 & 37 & 68 & 74 & 101 & 79 & 449 \\
\hline & $30 s$ & 27 & 86 & 56 & 49 & 22 & 30 & 270 \\
\hline & $40 \mathrm{~s}$ & 62 & 46 & 51 & 56 & 49 & 38 & 302 \\
\hline & $50 \mathrm{~s}$ & 40 & 39 & 46 & 33 & 53 & 52 & 263 \\
\hline & $60 \mathrm{~s}$ & 5 & 19 & 5 & 4 & 2 & 24 & 59 \\
\hline \multirow{5}{*}{$\begin{array}{c}\text { Age } \\
(\text { mean } \pm \\
\text { SD) }\end{array}$} & $20 \mathrm{~s}$ & $24.8 \pm 2.3$ & $25.6 \pm 2.1$ & $25.9 \pm 1.8$ & $26.1 \pm 2.0$ & $26.0 \pm 1.7$ & $24.9 \pm 1.9$ & $25.6 \pm 2.0$ \\
\hline & $30 \mathrm{~s}$ & $35.5 \pm 2.7$ & $34.2 \pm 2.7$ & $34.9 \pm 2.9$ & $35.1 \pm 3.2$ & $35.8 \pm 3.4$ & $33.3 \pm 2.8$ & $34.6 \pm 2.8$ \\
\hline & $40 s$ & $44.1 \pm 3.1$ & $44.7 \pm 2.7$ & $44.1 \pm 2.5$ & $44.5 \pm 3.0$ & $45.0 \pm 3.0$ & $45.8 \pm 3.0$ & $44.5 \pm 2.9$ \\
\hline & $50 \mathrm{~s}$ & $54.3 \pm 2.7$ & $55.0 \pm 3.1$ & $53.7 \pm 2.8$ & $53.7 \pm 3.1$ & $53.8 \pm 2.3$ & $54.4 \pm 2.9$ & $54.2 \pm 2.8$ \\
\hline & $60 \mathrm{~s}$ & $62.2 \pm 2.3$ & $62.6 \pm 1.6$ & $61.8 \pm 2.2$ & $62.3 \pm 2.1$ & $64.0 \pm 1.4$ & $62.1 \pm 2.0$ & $62.2 \pm 1.8$ \\
\hline
\end{tabular}


distinctly different.

\subsection{Scalp Features}

The moisture content of the vertex site was measured with DermaLab ${ }^{\oplus}$ USB moisture (CORTEX Technology, Denmark) which measures the electrical conductivity of the scalp. The scalp barrier function was evaluated as TEWL (Transepidermal water loss) using a Vapometer (Delfin Technologies, Kuopio, Finland). Sebumeter ${ }^{\oplus}$ SM 815 (Courage + Khazaka Electronic GmbH, Cologen, Germany) was used to measure scalp sebum excretion.

\subsection{Dandruff and Erythema}

Scalp condition was graded by evaluating $60 \times$ scalp photographs. The degree of dandruff and erythema were divided into five grades base on severity. The classification of dandruff was made in accordance with the Korea Food \& Drug Administration (KFDA): Grade 1: clean and healthy scalp without dandruff, Grade 2: a little dandruff was discovered, Grade 3: dandruff exists around most of the hair follicles, Grade 4: dandruff partly covered the scalp, Grade 5: more than half of the scalp surface was covered with dandruff. In addition, the grade of scalp erythema was divided in a similar way; Grade 1: healthy scalp with light and even tone, Grade 2: partly mottled and irregular color of scalp, Grade 3: partly reddish scalp, Grade 4: scalp redness revealed in half of the scalp, Grade 5: scalp redness revealed overall.

\subsection{Statistical Analysis}

Analysis between groups of subjects was performed using a Student's t-test. In all cases, tests with $p$-values $<0.05$ were considered statistically significant.

\section{Results}

\subsection{Hair Density and Diameter}

Commonly, hair density and diameter are considered as parameters of hair-loss. As shown in the photograph, hair density decreased and hair became thinner with ageing (Figure 2). There was $18 \%$ decrease between women in their $20 \mathrm{~s}$ $\left(159.6 \pm 35.9 \mathrm{~N} / \mathrm{cm}^{2}\right)$ to those in their $60 \mathrm{~s}\left(130.7 \pm 38.4 \mathrm{~N} / \mathrm{cm}^{2}\right.$ ) (Table 2, Figure $3(\mathrm{a}))$. On the other hand, the average hair diameter of all subjects peaked in their mid-40s $(89.0 \pm 12.8 \mu \mathrm{m}$ ), and then decreased (Table 2, Figure 3(b)).

Our previous study showed that hair density decreased about $25 \%$ in Korean women in their 60 s versus their 20s. In addition, the average hair diameter was the highest in their 20s in Korean and significantly decreased from the 50s to the 60s [6]. It implies that there are differences on hair-loss parameters with ageing between Asians.

\subsection{Hair Color}

The hair lightness value (L value) increased exponentially especially after 40 


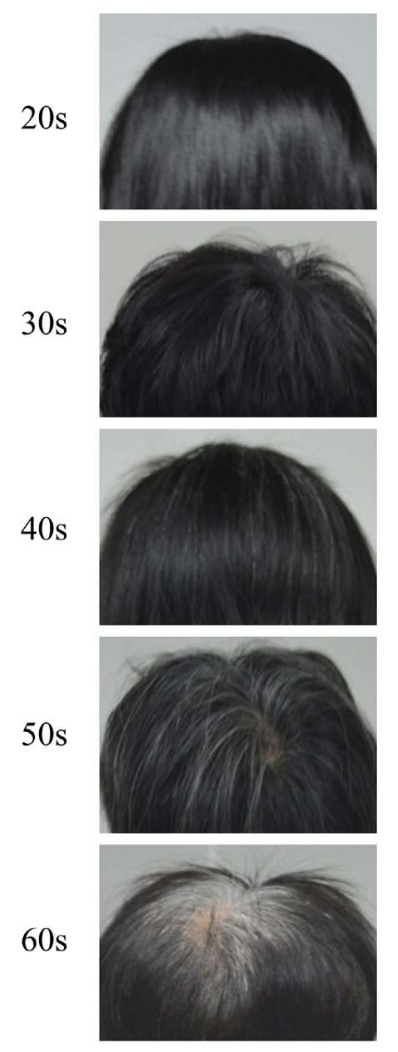

(a)
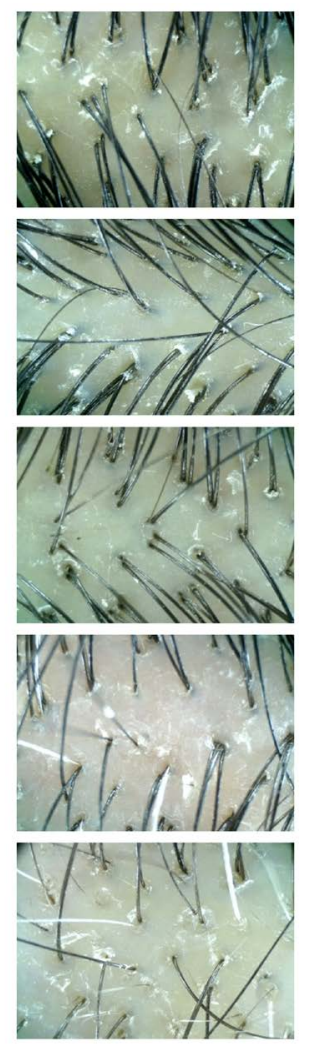

(b)

Figure 2. Changes with ageing in hair from 20s to 60 s. (a) Appearance of back hair. The amount of total hair decreases and graying hair is progressing. Hair is lacking in luster with ageing. (b) $60 \times$ Photographs on vertex area. Hair density and diameter change with ageing.

years of age (Table 2, Figure 3(c)). Hair color fadedness as well as gray hair increased in an age-dependent way. It was correlated with the result of visual evaluation which showed increased gray hair and color fadedness with ageing (Table 2). Hair lightness and gray-hair ratio increased significantly from $50 \mathrm{~s}$ in Korean [6]. However, as shown in Table 2, these factors tend to increase gradually with ageing in Chinese women.

\subsection{Scalp Features and Dandruff}

Transepidermal water loss (TEWL) was similar to subjects from 20 s to 40 s and significantly decreased in 50s. Interestingly, scalp water contents showed a similar degree over all ages, except for those in their 40s who had lower water contents (Table 2). The amount of scalp sebum tended to decrease with age (Table 2, Figure 4(a)). There were two points of age which showed rapid reduction: those at the beginning of their 40 s and $60 \mathrm{~s}$.

Most subjects had dandruff with more than a few levels, but the severity weakened with advancing age. Approximately $50 \%$ of those in their 20 s or 30 s 
Table 2. The changes of features in Chinese women's hair and scalp by ageing.

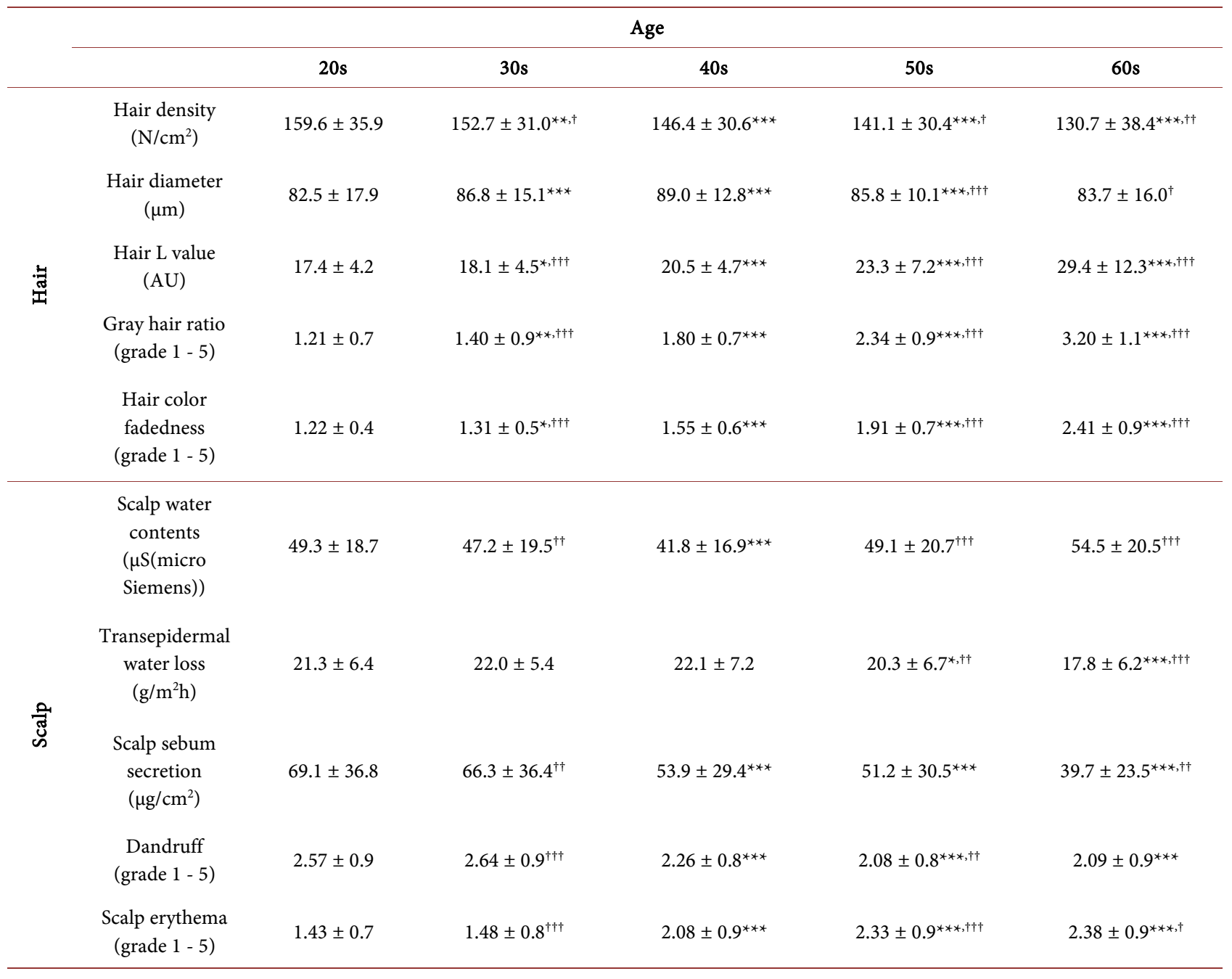

$($ Mean $\pm \mathrm{SD}) .{ }^{*} \mathrm{p}<0.05$ vs. 20 s group, ${ }^{* *} \mathrm{p}<0.01$ vs. 20 s group, ${ }^{* * *} \mathrm{p}<0.001$ vs. 20 s group. ${ }^{\dagger} \mathrm{p}<0.05$ vs. 40 s group, ${ }^{+\dagger} \mathrm{p}<0.01$ vs. 40 s group, ${ }^{,+\dagger} \mathrm{p}<0.001 \mathrm{vs.} 40 \mathrm{~s}$ group.

had more than mid-level dandruff when evaluated with 5 levels of dandruff severities: none, slight, moderate, severe and highly severe (Figure 4(c)). In women older than 40s, the number of people having severe dandruff (Grade 3 5) decreased, and about $20 \%$ of those in their 50 s or 60 s had clean scalp without dandruff (Grade 1). In short, more subjects of younger groups had dandruff, and the grade was more severe than in elderly groups as well.

\subsection{Scalp Erythema}

Skin erythema is characterized as redness or rash. We found that about $70 \%$ of those in their 20s or 30s showed light and even-toned scalp. Surprisingly, it was even worse in elderly groups, with more than $70 \%$ of their 40 s showing symptoms (Figure 4(d)). Grade 2 and 3 increased dramatically from 40s and maintained in their 50s and 60s. It was remarkable that the number of Chinese females suffering from scalp erythema has increased with ageing. 


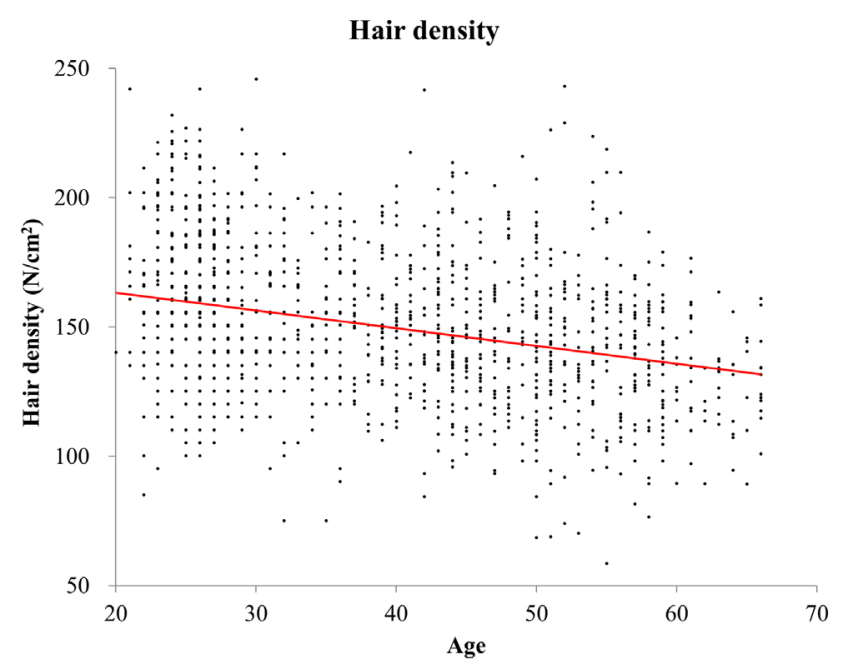

(a)

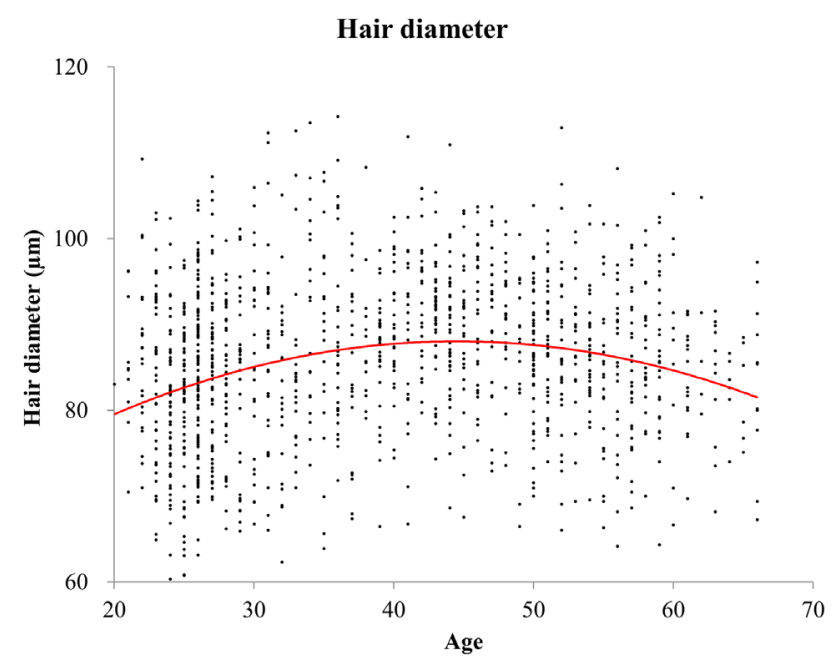

(b)

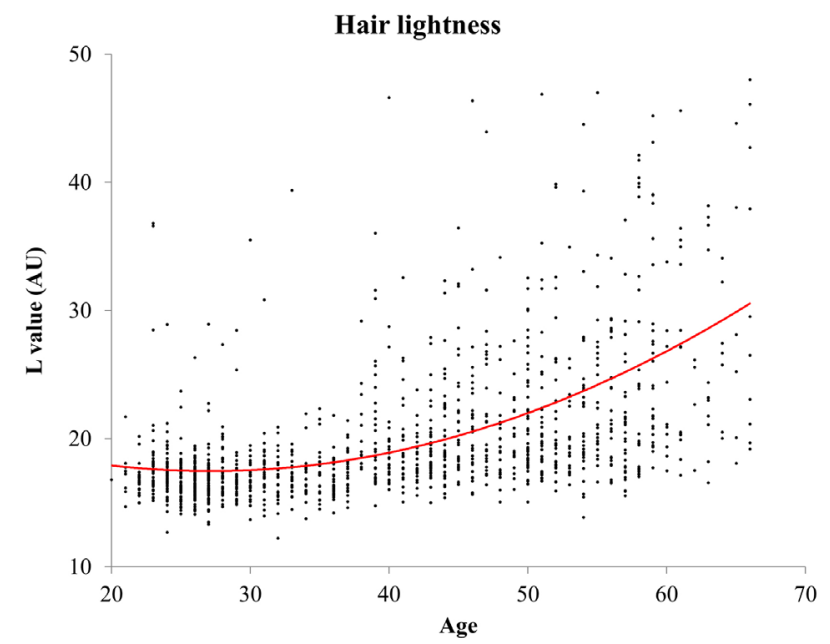

(c)

Figure 3. Features of ageing hair. (a) Hair density on vertex area decreased gradually after 20s. (b) Hair diameter reached peak on 40s then decreased. (c) Hair lightness value increases with ageing especially after 40 s. 


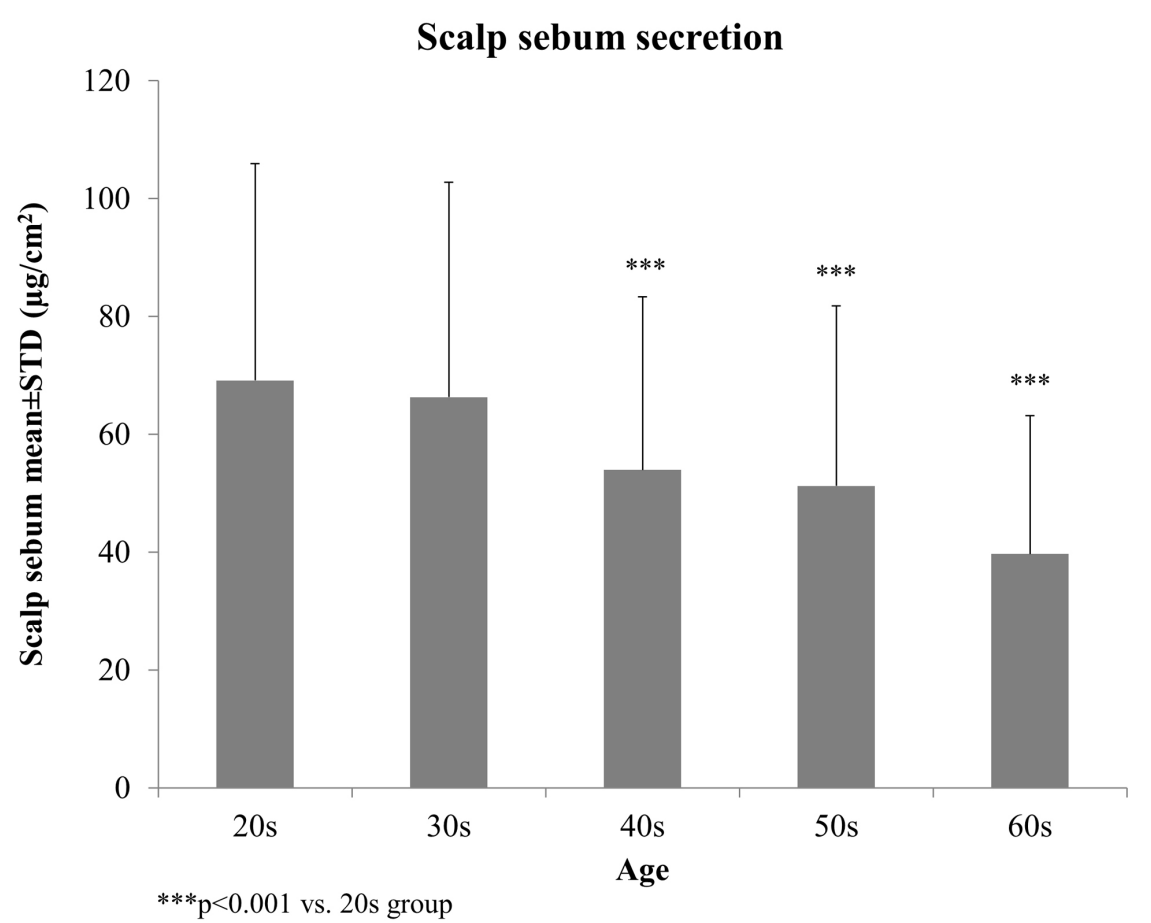

(a)

Frequency of washing hair

\begin{tabular}{cccccc}
\hline & 20s & 30s & 40s & 50s & 60s \\
\hline $\begin{array}{c}\text { Average } \\
\text { (days/week) }\end{array}$ & 3.8 & 3.0 & 3.0 & 2.4 & 1.9 \\
\hline
\end{tabular}

(b)

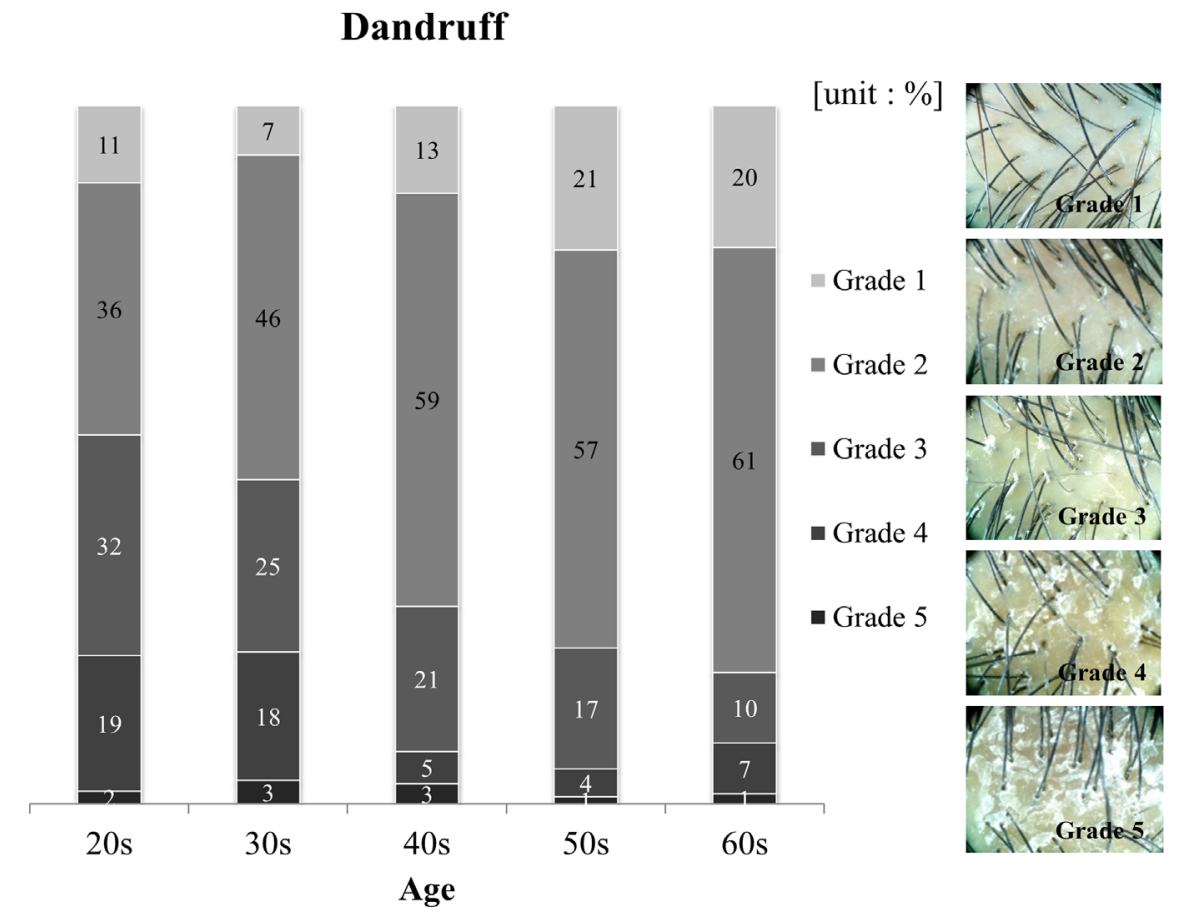

(c) 


\section{Scalp erythema}

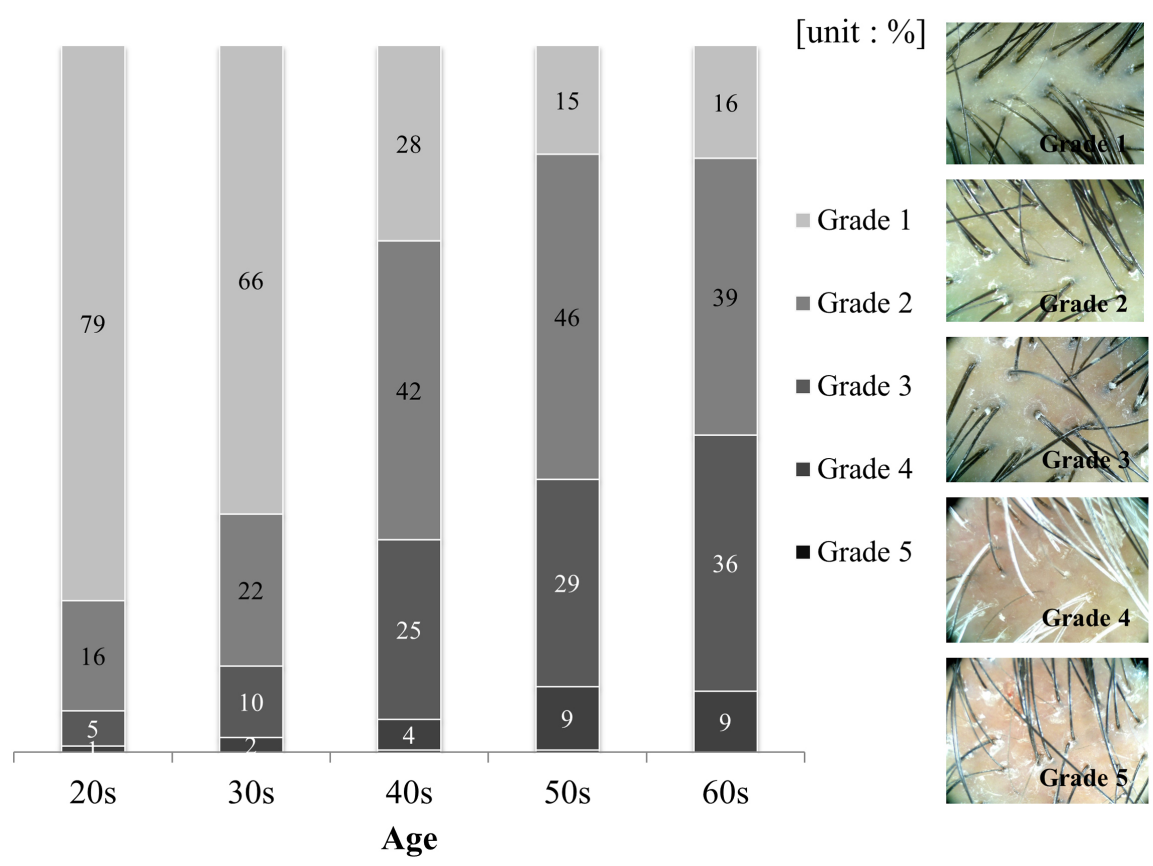

(d)

Figure 4. Features of ageing scalp. (a) Scalp sebum secretion got lowered over 40 s. ${ }^{* * *} \mathrm{p}<$ 0.001 vs. 20s group) (b) Frequency of washing hair per week revealed lower in elderly groups. (c) Scalp dandruff was evaluated to 5 grades by severity. Severe dandruff was shown more in young ages. (d) Scalp erythema was also divided to 5 grades. It shows severer with ageing.

\section{Discussion}

This is the first study of the features of Chinese women's scalp and hair, especially focusing on ageing. More than 1300 Chinese women were enrolled to this study. We also covered 6 representative metropolises in China.

Chinese females undergo a reduction of hair density as a common feature of ageing hair. The decline in Chinese women's hair diameter after reaching its peak in 40s is similar to other studies with Caucasian and Japanese people [10]. Hair graying is also one of the hallmarks of hair ageing [11]. As a result of investigator's evaluation, both hair graying and fading phenomenon increased in an age-dependent way as it is expected. Changes of hair lightness had a similar degree between women in their 20s and 30s, but in the 40s, the gap increased. Interestingly, through this study and our previous result, we found that at the time of the hair changes with ageing showed some differences between Chinese and Korean, such as hair diameter and hair lightness.

It was not just hair which changed as people got older, scalp did as well. First of all, the amount of scalp sebum and dandruff severity changed with ageing. It is well known that hormonal changes of females appear in their facial skin with the reduction of sebum secretion as they age [12] [13] [14], and scalp is not exceptional [15]. Unlike in women, the degree of sebum secretion keeps a high 
state in men. Since these differences are derived from sex hormones, female hormones, especially estrogen, are considered to be important hormones that affect the condition of women's scalp [16], and women undergo a reduction of sebum production after menopause [17]. We found that significant reduction of scalp sebum secretion was shown from 40 s of Chinese women compared to 20 s. Another interesting finding is that the relative amount of scalp sebum in Chinese women is 3 times higher than that of Korean women (data not shown).

In addition, scalp sebum is one of the important factors of dandruff. Sebaceous gland activity induces microfloral metabolism and makes flakes on the scalp [18]. This study showed that Chinese females had a relatively higher degree of dandruff in their 20 - 30s (grade 3 and 4), and the symptoms fell sharply in the early 40s. It is common to think that frequent hair washing leads to less dandruff. However we have surveyed the washing behaviour of hair, and younger Chinese women washed more frequently than older (Figure 4(b)). Therefore there might be the hormonal effect for this phenomenon. Unfortunately, because of limitation of our investigation, we cannot conclude the correlation of hormonal changes and sebum reduction and dandruff severity in Chinese women.

Another scalp condition, erythema, was exacerbated in the elderly groups, with dramatic increase in those over 40s. It is well known that seborrheic dermatitis causes erythema and desquamations of the skin in sebaceous gland rich area [19]. However, people with skin disorders that could affect this study were excluded. We can suggest that scalp conditions were worsening with ageing. This study is meaningful in finding out that scalp erythema is one of the ageing symptoms of scalp unlike the facial skin. There could be further studies of which factors are related to scalp erythema; for example, scalp skin barrier function, sensitive scalp features, or scalp microbiome.

It is well known that genetic background is the first determinant of skin characteristics [20], but recent studies showed that environmental factors (climate, food intake, life style, etc.) affect acquired skin features [21] [22] [23]. Scalp and hair might be influenced in a similar way to facial skin. We studied 6 cities in China because each has its own climate and environmental conditions which could affect the properties of the hair and scalp. Although we did not show the data, it was investigated whether the regional differences present or not. The hair density of the subjects from Shenyang was high, but their hair diameter was relatively lower than the average density or diameter of other cities. Interestingly, these differences are similar between Asian and Caucasian; hair density is higher in Caucasian [24], while hair diameter is higher in Asian [25]. In Wuhan, hair color became lighter rapidly over the age of 40s than average of other cities (data not shown). As a result, we found out several features which were appeared differently between regions in China. However, there are limits to defining the exact cause and tendency related to regional effects.

Despite such superficial phenomenon, this study is meaningful in respect of the first research for Chinese women's hair and scalp. It would be a good re- 
source to understand the changes of hair and scalp by ageing. Furthermore, it is necessary to investigate the regional study about climate, water, pollution, food, life style and hair care behaviour for further understanding the characteristics of scalp and hair in Chinese.

Both hair and scalp changed with ageing, but there was a difference in time of beginning. The features of hair changed continuously from 20s. On the other hand, the ageing features of scalp appeared remarkably from $40 \mathrm{~s}$. We suppose that the mechanism of aging between hair and scalp is different or just hair changes earlier than scalp.

\section{Acknowledgements}

We thank H.G. Park ${ }^{1}$, J.Y. Han ${ }^{1}$, E.J. Kim¹ ${ }^{1}$ Y. Gao ${ }^{2}$, J. $\mathrm{Liu}^{2}$ and Q. $\mathrm{He}^{2}$ for arranging and helping the clinical study.

\section{Conflict of Interest}

None.

\section{Financial Support}

Amorepacific R\&D funding.

\section{References}

[1] Birch, M.P., Messenger, J.F. and Messenger, A.G. (2001) Hair Density, Hair Diameter and the Prevalence of Female Pattern Hair Loss. British Journal of Dermatology, 144, 297-304. https://doi.org/10.1046/j.1365-2133.2001.04018.x

[2] Chen, W., Yang, C.C., Todorova, A., Al Khuzaei, S., Chiu, H.C., Worret, W.I. and Ring, J. (2010) Hair Loss in Elderly Women. European Journal of Dermatology, 20, 145-151.

[3] Keogh, E.V. and Walsh, R.J. (1965) Rate of Greying of Human Hair. Nature, 207, 877-878. https://doi.org/10.1038/207877a0

[4] Panhard, S., Lozano, I. and Loussouarn, G. (2012) Greying of the Human Hair: A Worldwide Survey, Revisiting the "50" Rule of Thumb. British Journal of Dermatology, 167, 865-873. https://doi.org/10.1111/j.1365-2133.2012.11095.x

[5] Van Neste, D. and Tobin, D.J. (2004) Hair Cycle and Hair Pigmentation: Dynamic Interactions and Changes Associated with Aging. Micron, 35, 193-200.

https://doi.org/10.1016/j.micron.2003.11.006

[6] Kim, S.N., Lee, S.Y., Choi, M.H., Joo, K.M., Kim, S.H., Koh, J.S., et al. (2013) Characteristic Ageing Features in Korean Women's Hair and Scalp. British Journal of Dermatology, 168, 1215-23. https://doi.org/10.1111/bjd.12185

[7] Tajima, M., Hamada, C., Arai, T., Miyazawa, M., Shibata, R. andIshino, A. (2007) Characteristic Features of Japanese Women's Hair with Aging and with Progressing Hair Loss. Journal of Dermatological Science, 45, 93-103. https://doi.org/10.1016/j.jdermsci.2006.10.011

[8] Wang, T.L., Zhou, C., Shen, Y.W., Wang, X.Y., Ding, X.L., Tian, S. and Wang, R.L. (2010) Prevalence of Androgenetic Alopecia in China: A Community-Based Study in Six Cities. British Journal of Dermatology, 162, 843-847. https://doi.org/10.1111/j.1365-2133.2010.09640.x 
[9] Kang, H., Kang, T.W., Lee, S.D., Park, Y.M., Kim, H.O. and Kim, S.Y. (2009) The Changing Patterns of Hair Density and Thickness in South Korean Women with Hair Loss: Clinical Office-Based Phototrichogram Analysis. International Journal of dermatology, 48, 14-21. https://doi.org/10.1111/j.1365-4632.2009.03795.x

[10] Robbins, C., Mirmirani, P., Messenger, A.G., Birch, M.P., Youngquist, R.S., Tamura, M. and Dawson, T.L. (2012) What Women Want-Quantifying the Perception of Hair Amount: An Analysis of Hair Diameter and Density Changes with Age in Caucasian Women. British Journal of Dermatology, 167, 324-332. https://doi.org/10.1111/j.1365-2133.2012.11010.x

[11] Wolff, K., Goldsmith, L., Katz, S., Gilchrest, B., Paller, A.S. and Leffell, D. (2007) Fitzpatrick's Dermatology in General Medicine. 7th Edition, McGraw-Hill, New York, 739-749, 963-973.

[12] Hall, G.K. and Phillips, T.J. (2004) Skin and Hormone Therapy. Clinical Obstetrics and Gynecology, 47, 437-449. https://doi.org/10.1097/00003081-200406000-00020

[13] Pochi, P.E., Strauss, J.S. and Downing, D.T. (1979) Age-Related Changes in Sebaceous Gland Activity. Journal of Investigative Dermatology, 73, 108-111. https://doi.org/10.1111/1523-1747.ep12532792

[14] Zouboulis, C. and Boschnakow, A. (2001) Chronological Ageing and Photoageing of the Human Sebaceous Gland. Clinical and Experimental Dermatology, 26, 600-607. https://doi.org/10.1046/j.1365-2230.2001.00894.x

[15] Piérard, G.E., Piérard-Franchimont, C., Lê, T. and Lapière, C. (1987) Patterns of Follicular Sebum Excretion Rate during Lifetime. Archives of Dermatological Research, 279, S104-S107. https://doi.org/10.1007/BF00585931

[16] Farage, M., Miller, K.W., Zouboulis, C.C., Piérard, G.E. and Maibach, H. (2012) Gender Differences in Skin Aging and the Changing Profile of the Sex Hormones with Age. Journal of Steroids and Hormonal Science, 3, 1. https://doi.org/10.4172/2157-7536.1000109

[17] Pochi, P.E. and Strauss, J.S. (1974) Endocrinologic Control to the Development and Activity of the Human Sebaceous Gland. Journal of Investigative Dermatology, 62, 191-201. https://doi.org/10.1111/1523-1747.ep12676783

[18] Ro, B.I. and Dawson, T.L. (2005) The Role of Sebaceous Gland Activity and Scalp Microfloral Metabolism in the Etiology of Seborrheic Dermatitis and Dandruff. Journal of Investigative Dermatology Symposium Proceedings, 10, 194-197. https://doi.org/10.1111/j.1087-0024.2005.10104.x

[19] Elewski, B.E. (2005) Clinical Diagnosis of Common Scalp Disorders. Journal of Investigative Dermatology Symposium Proceedings, 10, 190-193.

https://doi.org/10.1111/j.1087-0024.2005.10103.x

[20] Wesley, N.O. and Maibach, H.I. (2003) Racial (Ethnic) Differences in Skin Properties. American Journal of Clinical Dermatology, 4, 843-860.

https://doi.org/10.2165/00128071-200304120-00004

[21] Kim, E., Han, J., Park, H., Kim, M., Kim, B., Yeon, J. and Lee, H. (2017) The Effects of Regional Climate and Aging on Seasonal Variations in Chinese Women's Skin Characteristics. Journal of Cosmetics, Dermatological Sciences and Applications, 7, 164. https://doi.org/10.4236/jcdsa.2017.72014

[22] Rexbye, H., Petersen, I., Johansens, M., Klitkou, L., Jeune, B. and Christensen, K. (2006) Influence of Environmental Factors on Facial Ageing. Age and Ageing, 35, 110-115. https://doi.org/10.1093/ageing/afj031

[23] Engebretsen, K.A., Johansen, J.D., Kezic, S., Linneberg, A. and Thyssen, J.P. (2016) The Effect of Environmental Humidity and Temperature on Skin Barrier Function 
and Dermatitis. Journal of the European Academy of Dermatology and Venereolo$g y$, 30, 223-249. https://doi.org/10.1111/jdv.13301

[24] Loussouarn, G., El Rawadi, C. and Genain, G. (2005) Diversity of Hair Growth Profiles. International Journal of Dermatology, 44, 6-9. https://doi.org/10.1111/j.1365-4632.2005.02800.x

[25] Franbourg, A., Hallegot, P., Baltenneck, F., Toutaina, C. and Leroy, F. (2003) Current Research on Ethnic Hair. Journal of the American Academy of Dermatology, 48, S115-S119. https://doi.org/10.1067/mjd.2003.277

Submit or recommend next manuscript to SCIRP and we will provide best service for you:

Accepting pre-submission inquiries through Email, Facebook, LinkedIn, Twitter, etc. A wide selection of journals (inclusive of 9 subjects, more than 200 journals)

Providing 24-hour high-quality service

User-friendly online submission system

Fair and swift peer-review system

Efficient typesetting and proofreading procedure

Display of the result of downloads and visits, as well as the number of cited articles Maximum dissemination of your research work

Submit your manuscript at: http://papersubmission.scirp.org/

Or contact jcdsa@scirp.org 